\title{
Prevalence of Primary Pulmonary Multi-Drug Resistant Tuberculosis in and around Aligarh Region
}

Maryam Faridi1 ${ }^{*}$, Indu Shukla1, Nazish Fatima1', Sumit Varshney ${ }^{1}$ and Mohammad Shameem ${ }^{2}$

${ }^{1}$ Department of Microbiology, J.N. Medical College, AMU, Aligarh, Uttar Pradesh, India

${ }^{2}$ Department of TB and Respiratory Diseases, J.N. Medical College, AMU, Aligarh, Uttar Pradesh, India

\begin{abstract}
Tuberculosis (TB) is one of the most ancient diseases of mankind and has co-evolved with humans for many thousands of years or perhaps for several million years. M. tuberculosis strains that are resistant to the two most potent anti-TB drugs Isoniazid and Rifampicin, are termed as multidrug-resistant TB (MDR-TB) strains. Drug resistance is broadly classified as primary and acquired. Drug resistance in a patient who has never received anti-TB treatment previously or has taken treatment for less than a month is termed as primary resistance. Acquired resistance is the resistance which arises as a result of specific previous treatment. This study was aimed to determine the prevalence of primary MDR-TB in and around Aligarh region by molecular diagnostic method of Line probe assay (LPA). This two year study was carried out in culture and DST Laboratory (RNTCP certified), Department of Microbiology, J.N. Medical College AMU, Aligarh on the sputum samples received of the primary pulmonary tuberculosis suspected patients (according to PMDT guidelines) from the outpatient and inpatient departments of the hospital and from various tuberculosis units in and around Aligarh region from October 2015 to October 2017. Sputum samples were collected from suspected cases of primary pulmonary TB. These samples were subjected to routine microscopy and culture on LJ medium to detect Mycobacterium tuberculosis. Positive cases were subjected to drug sensitivity test by GenoType MTBDRplus Assay. Out of the total 514 samples collected, $265(51.56 \%)$ samples and $326(63.43 \%)$ samples were positive by ZN microscopy and fluorescent microscopy respectively. $312(60.70 \%)$ samples were positive on culture on LJ medium. Total 326 samples which were positive on fluorescent microscopy were subjected to LPA and $47(9.14 \%)$ samples were resistant to both rifampicin and isoniazid, $21(4.08 \%)$ samples were rifampicin mono-resistant and $31(6.03 \%)$ samples were isoniazid mono-resistant.
\end{abstract}

Keywords: Tuberculosis; Drug resistance; Microscopy

\section{Introduction}

Tuberculosis is an infectious bacterial disease caused by Mycobacterium tuberculosis which most commonly affects the lungs. It is transmitted from person to person via droplets from the throat and lungs of people with active pulmonary disease [1]. TB is a serious global public health threat. TB is the ninth leading cause of death worldwide and the leading cause from a single infectious agent, ranking above HIV/AIDS [2]. In 2016, there were an estimated 1.3 million TB deaths among HIV negative and an additional 374000 deaths among HIVpositive people [2]. Globally in 2016, an estimated $4.1 \%$ of new cases and $19 \%$ of previously treated cases had Multidrug resistant TB [2]. Rapid identification is important for effective treatment and control of MDR-TB. Conventional methods of drug susceptibility testing (DST) include solid media-based methods such as the proportion, absolute concentration, and resistance ratio methods. These can take up to 12 weeks to produce definitive results, leading to prolonged infectiousness [3]. Liquid media-based tests are more rapid, but also costlier and require sophisticated laboratories and trained personnel [3]. Molecular LPA permit rapid diagnosis of TB, isoniazid and rifampin resistance, and clinically relevant non- $M$. tuberculosis mycobacteria. In LPA assays, DNA or RNA is isolated from culture or direct (i.e., sputum) respiratory samples and then amplified and reverse hybridized onto a nitrocellulose strip with immobilized probes for different mycobacteria or for mutations that confer resistance. These strips can be quickly interpreted using a template, with the entire testing process taking a day or even less. The GenoType MTBDRplus (Hain Lifesciences, Nehren, Germany) identifies rifampin and isoniazid resistance by detecting the most common mutations of the $r p o B$ gene and the $k a t G$ and $i n h A$ genes, respectively.

\section{Materials and Methods}

Sputum samples from $514(\mathrm{n}=514)$ suspected new pulmonary TB patients were collected and subjected to $\mathrm{ZN}$ microscopy and fluorescent microscopy and cultured on LJ media. Sputum positive samples were tested by LPA for the presence of $M$. tuberculosis complex and resistance to isoniazid and rifampicin.

\section{LPA}

The GenoType MTBDRplus LPA was performed according to the manufacturer's (Hain Life-science, Nehren, Germany) instructions. Three steps for LPA test include DNA extraction, multiplex polymerase chain reaction (PCR) amplification and reverse hybridization. These steps were carried out in three separate rooms with restricted access and unidirectional workflow. LPA strips were observed and read for the presence of TUB band, amplification control band and conjugation control band and absence of any wild type (WT) band or presence of any mutation (MUT) band. The results were then interpreted as sensitive or resistant to any particular drug.

*Corresponding author: Dr. Maryam Faridi, Department of Microbiology, J.N Medical College, AMU, Aligarh, Uttar Pradesh, India, Tel: 0571522 8770; E-mail: maryamfaridi0@gmail.com

Received September 18, 2018; Accepted October 22, 2018; Published November 05, 2018

Citation: Faridi M, Shukla I, Fatima N, Varshney S, Shameem M (2018) Prevalence of Primary Pulmonary Multi-Drug Resistant Tuberculosis in and around Aligarh Region. J Med Microb Diagn 7: 285. doi:10.4172/2161-0703.1000285

Copyright: @ 2018 Faridi M, et al. This is an open-access article distributed under the terms of the Creative Commons Attribution License, which permits unrestricted use, distribution, and reproduction in any medium, provided the original author and source are credited. 
Citation: Faridi M, Shukla I, Fatima N, Varshney S, Shameem M (2018) Prevalence of Primary Pulmonary Multi-Drug Resistant Tuberculosis in and around Aligarh Region. J Med Microb Diagn 7: 285. doi:10.4172/2161-0703.1000285

\section{Results}

Out of $514(\mathrm{n}=514)$ sputum samples $256(51.56 \%)$ samples were positive by $\mathrm{ZN}$ microscopy and $326(63.43 \%)$ samples were positive by fluorescent microscopy. 312 (60.70\%) samples were culture positive on L J media (Table 1 and Figure 1).

Out of total 326 samples subjected to LPA, 6 samples were TUB band negative and 320 samples were TUB band positive (Table 2 and Figure 2).

The anti-mycobacterial sensitivity profile observed on LPA was such that $21(4.08 \%)$ samples were mono-resistant to rifampicin, 31 (6.03\%) samples were mono-resistant to isoniazid and $47(9.14 \%)$ samples were observed to be resistant to both isoniazid and rifampicin (Table 3 and Figure 3).

\section{Discussion}

In our study out of the total 514 samples, 265 (51.56\%) were AFB positive and 249 (48.44\%) were smear negative. In a similar study by Tripathy et al. reported $47.65 \%$ cases were smear positive for AFB which is comparable to our study [4]. Mukherjee et al. in their study found $38.64 \%$ samples positive by $\mathrm{ZN}$ staining [5].

The present study showed that out of total 514 samples, $326(63.43 \%)$

\begin{tabular}{|c|c|c|c|}
\hline $\begin{array}{c}\text { Total no. of } \\
\text { patients }\end{array}$ & $\begin{array}{c}\text { ZN smear } \\
\text { positive no. (\%) }\end{array}$ & $\begin{array}{c}\text { Fluorescent } \\
\text { microscopy } \\
\text { positive no. (\%) }\end{array}$ & $\begin{array}{c}\text { Mycobacterial } \\
\text { culture positive } \\
\text { no. (\%) }\end{array}$ \\
\hline 514 & $265(51.56 \%)$ & $326(63.43 \%)$ & $312(60.70 \%)$ \\
\hline
\end{tabular}

Table 1: Comparison of $\mathrm{ZN}$ smear examination, fluorescent microscopy and mycobacterial culture on LJ medium of MDR-TB suspected patients $(n=514)$.

\begin{tabular}{|c|c|c|c|c|c|}
\hline \multicolumn{2}{|c|}{ Tub Band Positive } & \multicolumn{2}{|c|}{ Tub Band Negative } & \multicolumn{2}{|c|}{ Total LPA } \\
\hline \multicolumn{2}{|c|}{$320(98.16 \%)$} & \multicolumn{2}{|c|}{$6(1.84 \%)$} & \multicolumn{2}{|c|}{$326(100 \%)$} \\
\hline \multicolumn{6}{|c|}{ Table 2: TUB band of the samples. } \\
\hline $\begin{array}{l}\text { No. of } \\
\text { patients }\end{array}$ & $\begin{array}{c}\text { MDR } \\
(\mathrm{R}+\mathrm{H})(\%)\end{array}$ & $\begin{array}{c}\text { Mono-resistant } \\
\text { R (\%) }\end{array}$ & $\begin{array}{c}\text { Mono-resistant } \\
\text { H (\%) }\end{array}$ & $\begin{array}{c}\text { Sensitive } \\
(\mathrm{R}+\mathrm{H}) \\
(\%)\end{array}$ & Total $(\%)$ \\
\hline 514 & $47(9.14 \%)$ & $21(4.08 \%)$ & $31(6.03 \%)$ & $\begin{array}{c}221 \\
(42.30 \%)\end{array}$ & $514(100 \%)$ \\
\hline
\end{tabular}

Table 3: Anti-mycobacterial sensitivity profile of primary pulmonary tuberculosis suspected patients as detected by LPA $(n=514)$.
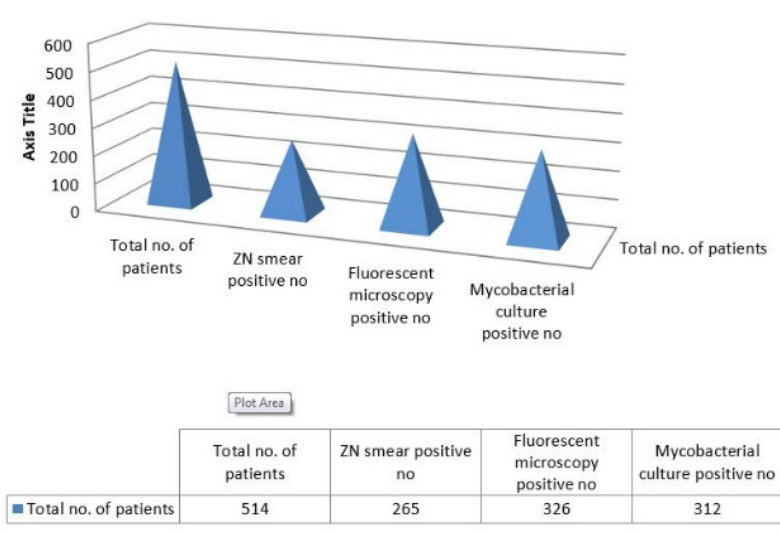

Figure 1: Comparison of $\mathrm{ZN}$ smear examination, fluorescent microscopy and mycobacterial culture on LJ medium of MDR-TB suspected patients.

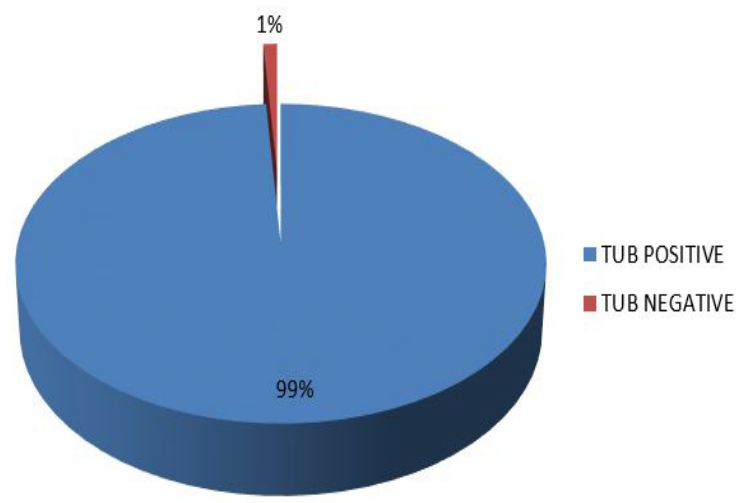

Figure 2: LPA result.

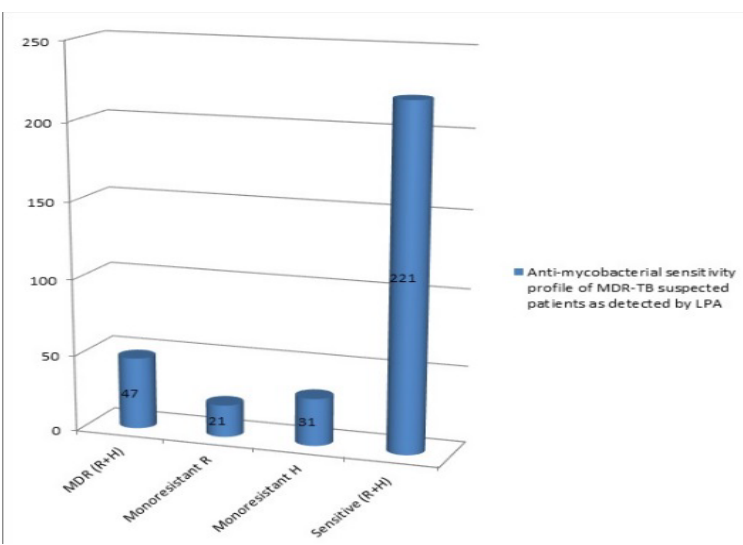

Figure 3: Anti-mycobacterial sensitivity profile of primary pulmonary tuberculosis suspected patients as detected by LPA.

samples were positive for fluorescent microscopy and 188 (36.57\%) were negative. The study clearly indicated that the case detection rate of fluorescent microscopy is remarkably higher than that of $\mathrm{ZN}$ microscopy. The other advantages of less eye strain, easy visualization, less time consumption and even detection of low number of bacteria in comparison to $\mathrm{ZN}$ method cannot be overlooked also.

In the present study, out of 514 samples $312(60.70 \%)$ samples were positive for culture on LJ media and $183(35.60 \%)$ samples were negative however, 19 (3.70\%) samples were dry/contaminated. Kelamine et al. in their study also faced contamination rate of 3\% [6]. Singh et al. reported $4.9 \%$ contamination in their study [7].

In this study positivity rate of $\mathrm{ZN}$ microscopy, fluorescent microscopy and mycobacterial culture positive were $265(53.53 \%)$, $326(65.85 \%)$ and $312(63.03 \%)$ respectively. In a similar study by Laifangbam et al. $44.1 \%, 71.6 \%$ and $70 \%$ cases were found positive by $\mathrm{ZN}$, fluorescent microscopy and culture respectively, which is comparable to the data achieved in our study [8]. In another study by Laifangbam et al. positivity rates for $\mathrm{ZN}$ microscopy, fluorescent microscopy, and culture were $36.1 \%, 74.1 \%$, and $72.2 \%$, respectively which is again close to the data of our study however positivity rate of $\mathrm{ZN}$ microscopy in our study is quite high [8].

In our study 514 samples were subjected to microscopy, out of 514 samples 326 fluorescent microscopy positive samples were further subjected to LPA. TUB bands were present in 320 (98.16\%) samples out 
Citation: Faridi M, Shukla I, Fatima N, Varshney S, Shameem M (2018) Prevalence of Primary Pulmonary Multi-Drug Resistant Tuberculosis in and around Aligarh Region. J Med Microb Diagn 7: 285. doi:10.4172/2161-0703.1000285

of the total 326 samples subjected to LPA and TUB bands were absent in $6(1.84 \%)$ samples. In the present study, on the basis of LPA $47(9.14 \%)$ samples were found to be resistant to both rifampicin and isoniazid, mono-resistant to rifampicin were 21 (4.08\%) samples, mono-resistant to isoniazid were $31(6.03 \%)$ samples and 221 samples were sensitive to both isoniazid and rifampicin. Different observations of rates of MDR have been made by LPA at different times. 3.5\% of primary MDR-TB was documented by Global TB report 2014 [9]. In 2015 MDR-TB was reported 3.9\% in Global TB report [10]. Global TB report 2017 has documented primary MDR at $4.1 \%$ [2]. The prevalence of MDR-TB varies between 0.07 to $5.7 \%$ across India [11-17]. A study by Desikan et al. showed their $19.1 \%$ isolates were MDR, $10.6 \%$ were rifampicin mono-resistant, $8.3 \%$ were isoniazid mono-resistant and $61.9 \%$ strains were found to be pan-sensitive [18]. A similar study by Almeida et al. showed MDR in $30 \%$ of new cases [19]. Mathuria et al. in their study reported primary drug resistance of $13.3 \%$ in Varanasi, Uttar Pradesh; 7.1\% in Sawaimadhopur, Rajasthan; 25\% in Buxar, Bihar [20] Gaude et al. reported $11.1 \%$ primary drug resistance in their study in Kranataka [21]. Jain et al. reported primary drug resistance of $13.2 \%$ in a study in Lucknow [22]. In a similar study by Agwan et al. in Meerut primary MDR came out to be $7.2 \%$ which is quite comaparable to our data and they showed, $17.3 \%$ rifampicin mono-resistant and $4.5 \%$ isoniazid mono-resistant [23].

\section{Conclusion}

In this study the prevalence of primary pulmonary multidrug resistant tuberculosis was found to be $9.14 \%$ and isoniazid monoresistance was found to be $6.03 \%$ and rifampicin monoresistance was reported as $4.08 \%$. Keeping in mind the socio-economic status of the patients seeking medical service in the institute, this much high prevalence of drug resistant TB can be justified however, factor that lead to clustering of data like we were primarily concerned with the TB patients in the institute itself cannot be overlooked.

\section{References}

1. Hirsh AE, Tsolaki AG, DeRiemer K, Feldman MW, Small PM (2004) Stable association between strains of Mycobacterium tuberculosis and their human host populations. Proc Natl Acad Sci USA 101: 4871.

2. WHO (2017) Global TB report 2: 1.

3. Heifets LB, Cangelosi GA (1999) Drug susceptibility testing of Mycobacterium tuberculosis: A neglected problem at the turn of the century (State of the Art). Int J Tuberc Lung Dis 3: 564-581.

4. Tripathy S, Kumar R, Singh SD (2015) Prevalence of multidrug resistant pulmonary tuberculosis in North Bihar. J Clin Diagn Res 9: LC09.

5. Mukherjee A, Saha I, Sarkar A, Chowdhury R (2012) Gender differences in notification rates, clinical forms and treatment outcome of tuberculosis patients under the RNTCP. Lung India: Official Organ of Indian Chest Society 29: 120.

6. Kelamane S, Mispah P (2017) Sensitivity and specificity of conventional fluorescent microscopy to diagnose pulmonary tuberculosis among pulmonary tuberculosis symptomatics in Karimnagar. Sch J App Med Sci 5: 391-395.
7. Singh BK, Sharma SK, Sharma R, Sreenivas V, Myneedu VP, et al. (2017) Diagnostic utility of a line probe assay for multidrug resistant-TB in smearnegative pulmonary tuberculosis. Plos one 12: e0182988.

8. Laifangbam S, Huidrom LS, Khumanthem SD (2013) Detection of Mycobacterium tuberculosis by three methods and their correlation to chest $X$-ray findings and CD4 T-lymphocyte counts in human immunodeficiency virus-pulmonary tuberculosis coinfection. J Med Soc 27: 203.

9. WHO (2014) Global TB report.

10. WHO (2015) Global TB report.

11. Ramachandran R, Nalini S, Chandrasekar V, Dave PV, Sanghvi AS, et al. (2009) Surveillance of drug-resistant tuberculosis in the state of Gujarat, India Int J Tuberc Lung Dis 13: 1154-1160.

12. Aziz MA, Wright A, Laszlo A, De Muynck A, Portaels F, et al. (2006) Epidemiology of anti-tuberculosis drug resistance (The Global Project on Antituberculosis Drug Resistance Surveillance): An updated analysis. The Lancet 368: 2142-2154.

13. Datta BS, Hassan G, Kadri SM, Qureshi W, Kamili MA, et al. (2009) Multidrugresistant and extensively drug resistant tuberculosis in Kashmir, India. J Infect Dev Ctries 4: 19-23.

14. Myneedu VP, Singhal R, Khayyam KU, Sharma PP, Bhalla M, et al. (2015) First and second line drug resistance among treatment naïve pulmonary tuberculosis patients in a district under Revised National Tuberculosis Control Programme (RNTCP) in New Delhi. J Epidemiol Glob Health 5: 365-373.

15. Mahadev B, Kumar P, Agarwal SP, Chauhan LS, Srikantaramu N (2005) Surveillance of drug resistance to anti-tuberculosis drugs in districts of Hoogli in West Bengal and Mayurbhanj in Orissa. India J Tuberc 52: 5-10.

16. Das D, Dwibedi B, Kar SK (2014) Low levels of anti TB drug resistance in Rayagada district of Odisha, India. Int J Mycobacteriol 3: 76-78.

17. Sharma SK, Kumar S, Saha PK, George N, Arora SK, et al. (2011) Prevalence of multidrug-resistant tuberculosis among category II pulmonary tuberculosis patients. Indian J Med Res 133: 312-315.

18. Desikan P, Panwalkar N, Mirza SB, Chaturvedi A, Ansari K, et al. (2017) Line probe assay for detection of Mycobacterium tuberculosis complex: An experience from Central India. Indian J Med Res 145: 70.

19. Almeida D, Rodrigues C, Udwadia ZF, Lalvani A, Gothi GD, et al. (2003) Incidence of multidrug-resistant tuberculosis in urban and rural India and implications for prevention. Clin Infect Dis 36: e152-e154.

20. Mathuria JP, Samaria JK, Srivastava GN, Mathuria BL, Ojha SK, et al. (2013) Primary and acquired drug resistance patterns of Mycobacterium tuberculosis isolates in India: A multicenter study. J Infect Public Health 6: 456-464.

21. Gaude GS, Hattiholli J (2015) Drug resistance patterns among pulmonary tuberculosis patients in a tertiary care hospital in northern Karnataka. Journal of Medicine in the Tropics 17: 81

22. Jain A, Mondal R, Prasad R, Singh K, Ahuja RC (2008) Prevalence of multidrug resistant Mycobacterium tuberculosis in Lucknow, Uttar Pradesh. Indian J Med Res 128: 300 .

23. Agwan V, Kansal R, Madan M, Asthana AK (2015) Primary multi drug resistance in new pulmonary tuberculosis patients in Western Uttar Pradesh, India. Int $J$ Curr Microbiol App Sci 4: 656-663. 